\title{
A new synthetic chalcone derivative, 2-hydroxy-3',5,5'- trimethoxychalcone (DK-139), suppresses the Toll-like receptor 4-mediated inflammatory response through inhibition of the Akt/NF-kB pathway in BV2 microglial cells
}

\author{
Young Han Lee ${ }^{1}$, Seung-Hyun Jeon ${ }^{1}$, \\ Se Hyun $\mathrm{Kim}^{2}$, Changyoun Kim ${ }^{1}$, \\ Seung-Jae Lee ${ }^{1}$, Dongsoo Koh ${ }^{3}$, \\ Yoongho $\mathrm{Lim}^{4}$, Kyooseob Ha, ${ }^{5,6}$ and \\ Soon Young Shin ${ }^{1,6}$ \\ ${ }^{1}$ Department of Biomedical Science and Technology \\ Research Center for Transcription Control \\ SMART Institute of Advanced Biomedical Science \\ Konkuk University \\ Seoul 143-701, Korea \\ ${ }^{2}$ Institute of Human Behavioral Medicine \\ Seoul National University College of Medicine \\ Seoul 110-744, Korea \\ ${ }^{3}$ Department of Applied Chemistry \\ Dongduk Women's University \\ Seoul 136-714, Korea \\ ${ }^{4}$ Division of Bioscience and Biotechnology \\ BMIC, Konkuk University \\ Seoul 143-701, Korea \\ ${ }^{5}$ Mood Disorders Clinic and Affective Neuroscience Laboratory \\ Department of Neuropsychiatry \\ Seoul National University Bundang Hospital \\ Seongnam 463-707, Korea \\ ${ }^{6}$ Corresponding authors: Tel, 82-2-2030-7946; \\ Fax, 82-2-3437-9781; E-mail, shinsy@konkuk.ac.kr (S.Y.S) \\ Tel, 82-31-787-7431; Fax, 82-31-787-4058; \\ E-mail, kyooha@snu.ac.kr (K.H.) \\ http://dx.doi.org/10.3858/emm.2012.44.6.042
}

Accepted 27 February 2012

Available Online 29 February 2012

Abbreviations: AKTi, inhibitor of Akt1/2; IKK, IKB kinase; SEAP, secreted embryonic alkaline phosphatase; TLR4, Toll-like receptor 4

\begin{abstract}
Microglial cells are the resident innate immune cells that sense pathogens and tissue injury in the central nervous system (CNS). Microglial activation is critical
\end{abstract}

for neuroinflammatory responses. The synthetic compound 2-hydroxy-3',5,5'-trimethoxychalcone (DK-139) is a novel chalcone-derived compound. In this study, we investigated the effects of DK-139 on Toll-like receptor 4 (TLR4)-mediated inflammatory responses in BV2 microglial cells. DK-139 inhibited lipopolysaccharide (LPS)-induced TLR4 activity, as determined using a cell-based assay. DK-139 blocked LPS-induced phosphorylation of $I_{\kappa} B$ and p65/RelA NF- $k B$, resulting in inhibition of the nuclear translocation and trans-acting activity of NF-KB in BV2 microglial cells. We also found that DK-139 reduced the expression of NF- $\mathrm{KB}$ target genes, such as those for COX-2, iNOS, and IL-1 $\beta$, in LPS-stimulated BV2 microglial cells. Interestingly, DK-139 blocked LPS-induced Akt phosphorylation. Inhibition of Akt abrogated LPS-induced phosphorylation of p65/RelA, while overexpression of dominant-active p110CAAX enhanced p65/RelA phosphorylation as well as $\mathrm{iNOS}$ and COX2 expression. These results suggest that DK-139 exerts an anti-inflammatory effect on microglial cells by inhibiting the Akt//KB kinase (IKK)/NF-KB signaling pathway.

Keywords: chalcone; lipopolysaccharides; microglia; NF-kB; proto-oncogene proteins c-akt; Toll-like receptor 4

\section{Introduction}

Neuroinflammation is an important defense mechanism against infectious agents and neuronal injuries in the central nervous system (CNS). However, excessive or sustained neuroinflammatory processes may result in the neuronal damage observed in many neurodegenerative disorders, such as Alzheimer's, Parkinson's, and Huntington's diseases (Nimmo and Vink, 2009). Microglial cells are the resident macrophage-like immune cells that act as the primary responding cells during infection and injury in the CNS (Czeh et al., 2011). Microglial cells are highly mobile and are rapidly activated by 
various neuronal injuries, stress, and infection. Activated microglial cells produce various inflammatory mediators, including tumor necrosis factor-alpha (TNF- $\alpha$ ), interleukin (IL)-1 $\beta$, IL-6, nitric oxide (NO), reactive oxygen species (ROS), and prostaglandin $\mathrm{E}_{2}$, which may be neurotoxic (Graeber and Streit, 2010). Since excessive neuroinflammation can cause the pathologic processes that underlie many neurodegenerative disorders, it is important to modulate the inflammatory responses induced by the activated microglia.

Flavonoids are secondary metabolites found in many dietary plants. Many flavonoids have diverse pharmacologic activities, including antioxidative and anti-inflammatory properties (Pietta, 2000; Yao et al., 2004). Flavonoids contain a common C6-C3-C6 skeleton, which consists of three rings $(A, C$, and $B)$, and they can be divided into several classes, e.g., chalcones, flavonols, flavones, flavanones, anthocyanidins, and isoflavonoids, based on the structural substituent. Of these, chalcone is an open-chain flavonoid that bears two aromatic rings (A and $B$ ) linked by a three-carbon enone moiety (Orlikova et al., 2011). Chalcone derivatives have a variety of biological properties, including antioxidant, antibacterial, antitumorigenic and anti-inflammatory activities (Yadav et al., 2011). Although chalcone derivatives have very similar chemical structures, the mechanisms of their cellular activities are quite different (Yadav et al., 2011). Moreover, the bioactive principles and molecular mechanisms responsible for the anti-inflammatory activities of the chalcones in the microglia remain to be elucidated.

$\mathrm{NF}-\mathrm{kB}$ is an essential transcription factor that regulates inflammatory responses through modulation of the expression of various pro-inflammatory mediators, including cytokines, chemokines, and $\mathrm{NO}$, in the microglia. By studying structure-activity relationships (SAR), we found that the 3',5'-dimethoxy groups on the B-ring of chalcones are important for the inhibition of TNF- $\alpha$-induced NF- $\mathrm{KB}$ activation in human colon cancer cells (Shin et al., 2011a). In the present study, we synthesized a new chalconebased compound, (E)-3-(3,5-dimethoxyphenyl)-1(2-hydroxy-5-methoxyphenyl)prop-2-en-1-one), which bears 3',5'-dimethoxy groups on the B-ring and a 5-monomethoxy group on the A-ring (2-hydroxy-3',5,5'-trimethoxychalcone, termed DK139; Figure 1), and investigated its inhibitory effects on the lipopolysaccharide (LPS)-induced inflammatory responses of microglial cells. Our results demonstrate that DK-139 blocks LPS-induced expression of NF-kB target genes, such as iNOS and COX2, as well as the production of pro-inflammatory cytokines, including IL-1 $\beta$ and IL-6. Further analyses revealed that DK-139

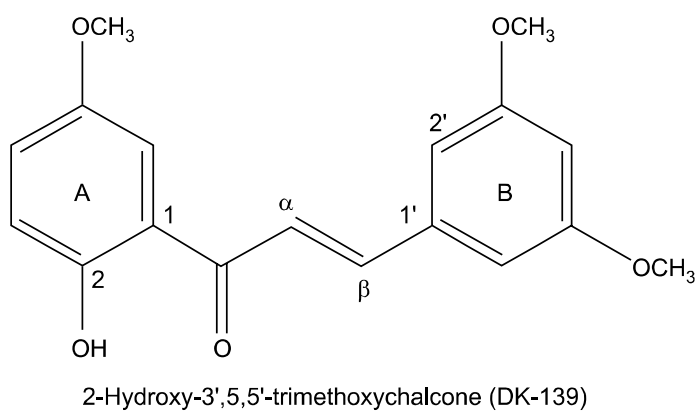

Figure 1. The chemical structure of DK-139.

blocked the LPS-induced NF-kB pathway through inhibition of Akt (protein kinase B). The present study provides the novel chalcone-based compound DK-139 as a potential candidate agent for inhibition of the Akt/NF-kB pathway in the microglia.

\section{Results}

\section{DK-139 inhibits LPS-induced TLR4 activity}

LPS induces inflammatory responses via the production of several pro-inflammatory mediators (Jeong et al., 2010). The cellular receptor for LPS has been identified as TLR4 (Chow et al., 1999). Using a cell-based assay, we tested LPS-induced TLR4 activity in HEK293 cells that expressed hTLR4 and MD-2/CD14 coreceptor genes and a secreted embryonic alkaline phosphatase (SEAP) reporter gene (HEK-Blu-hTLR4). When these cells were stimulated with LPS, TLR4 activity was enhanced in a dose-dependent manner (Figure 2A). To identify a novel compound that could inhibit TLR4-mediated inflammatory responses, we screened approximately 200 novel chalcone-derived synthetic chemicals, and found that the DK-139 compound was the most potent blocker of LPS-induced TLR4 activity (data not shown). Figure 2B shows the dose-dependent effect of DK-139 on the inhibition of LPS-induced TLR4 activity in HEK-Blu-hTLR4 cells.

\section{DK-139 inhibits TLR4-mediated NF-KB activation in BV2 rat microglial cells}

$\mathrm{NF}-\kappa \mathrm{B}$ activation is important for the expression of diverse inflammatory mediators and controls the pathologic outcomes in acute and chronic inflammatory diseases (Barnes and Karin, 1997). The NF-kB complex is usually retained in the cytoplasm and its activation is tightly controlled by IKB (NFKBIA), which inhibits the nuclear localization 
A

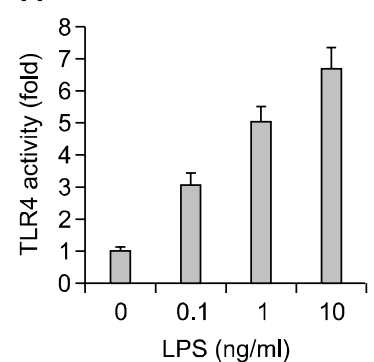

B

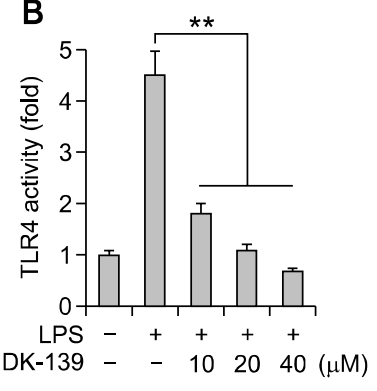

Figure 2. Effect of DK-139 on LPS-induced TLR4 activity. HEK-Blue ${ }^{T M}$-hTLR4 cells were treated with different concentrations of LPS (A) or $10 \mathrm{ng} / \mathrm{ml}$ LPS in the absence or presence of DK-139 (B). After $12 \mathrm{~h}$, SEAP activity was measured using a microplate reader at $650 \mathrm{~nm}$. The data shown represent the means $\pm S D$ of three independent experiments performed in triplicate. ${ }^{* *} P<0.01$.

of NF-kB. LPS stimulation of TLR4 induces degradation of $I_{\kappa} B$ through the activation of $I_{\kappa} B$ kinase (IKK), which leads to activation of NF- $\mathrm{KB}$. To investigate whether DK-139 modulates the NF-kB pathway in microglia, BV2 microglial cells were pretreated with DK-139 for 30 min before LPS stimulation. Western blot analysis showed that pretreatment with DK-139 substantially abrogated LPS-induced phosphorylation of both $I_{\kappa} B$ and p65/RelA (Figure 3A).

To confirm the inhibitory effect of DK-139 on NF- $k B$, the translocation of p65/RelA was examined using immunofluorescence microscopy. Staining for phospho-p65/RelA at Ser-468 was positive in the nucleus in response to LPS treatment, and this staining was completely lost in the presence of DK-139 (Figure 3B), which indicates that DK-139 efficiently blocks the nuclear translocation of NF-kB upon LPS stimulation through the inhibition of the I B upstream kinase in BV2 microglial cells. To investigate further whether DK-139 affects NF-kB transcriptional activity, we tested NF-kB-dependent transcription using an NF-kB cis-acting reporter assay system. BV2 microglial cells were transfected with the $5 \times N F-k B-l u c$ plasmid that contains five repeats of the NF-KB binding site. In this case, luciferase reporter activity represents the DNAbinding and transcriptional activities of NF- $\mathrm{KB}$. As shown in Figure 3C, LPS enhanced 18-fold the NF-kB-dependent transcriptional activity. When cells were pretreated with DK-139, the LPS-induced reporter activity was dose-dependently reduced. These results demonstrate that DK-139 blocks the TLR4-mediated nuclear translocation and transactivating activity of NF-KB.

\section{DK-139 reduces the expression of TLR4-mediated NF- $\mathrm{KB}$ target genes}

NF-kB activated by TLR4 stimulates the expression of diverse proinflammatory mediators. To characterize the inhibitory effect of DK-139 on TLR4-induced activation of NF-kB, BV2 microglial cells were pretreated with DK-139 for $30 \mathrm{~min}$ before the addition of LPS for $12 \mathrm{~h}$, after which the mRNA levels of NF-KB target genes were measured by RT-PCR. DK-139 pretreatment resulted in the suppression of LPS-induced accumulations of iNOS, COX2, and IL $1 \beta$ mRNA (Figure 4A). Similar results were observed for primary cultured rat microglia (Supplemental Data Figure S1). DK-139 also significantly reduced the level of LPS-produced NO, which is an end-product of iNOS (Figure 4B). Under these conditions, cell viabilities were not altered within $24 \mathrm{~h}$ of the application of DK-139 (Supplemental Data Figure S2), indicating that suppression of NF-KB target gene expression by DK-139 is not due to its cytotoxic effect. Thus, these results suggest that inhibition of NF-KB by DK-139 results in the suppression of NF-kB target gene expression.

\section{Docking of DK-139 into the ATP-binding pocket of Akt}

Multiple signaling pathways, such as PI3K/Akt and mitogen-activated protein kinase (MAPK), are involved in the nuclear translocation and transactivation potential of NF-kB by activating IKK (Madrid et al., 2000, 2001). It has been reported that isobavachalcone, a natural chalchone derivative, inhibits Akt through binding to the ATP-binding pocket of Akt1 (Jing et al., 2010). To elucidate whether DK139 binds to Akt, an in silico docking study was carried out. In accordance with the previous report (Jing et al., 2010), isobavachalcone formed four $\mathrm{H}$-bonds with R6, K181, E230, and A232 (Figure 5A, left; Supplemental Data Figure S3A). Similarly, DK-139 formed four $\mathrm{H}$-bonds with S9, K181, E236, and T292 (Figure 5A, right; Supplemental Data Figure S3B). While isobavachalcone showed hydrophobic interactions with 14 residues of Akt protein, DK-139 had hydrophobic interactions with nine residues. Comparing the residues participating with $\mathrm{H}$-bonds and the hydrophobic interactions with isobavachalcone to those with DK-139, ten residues are identical in both. In addition, when the 3D structure of DK-139 contained in the binding pocket was compared with that of isobavachalcone, DK-139 fitted into the hydrophobic ATP-binding pocket in the kinase domain of Akt1 in the similar manner as isobavachalcone (Figure 5B; Supplemental Data Figures S4 and S5). These data suggest that 
A

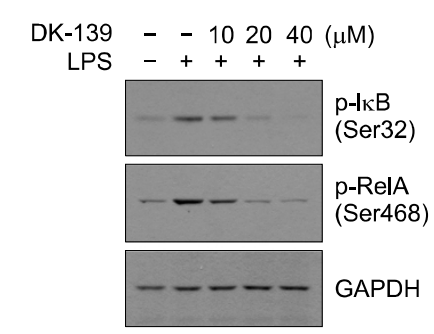

C

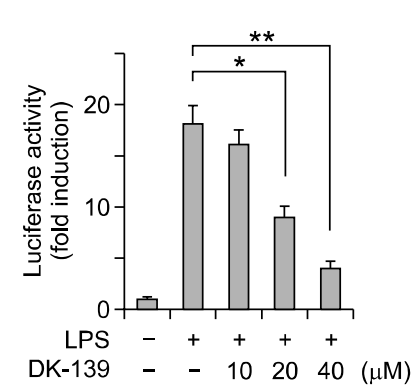

B

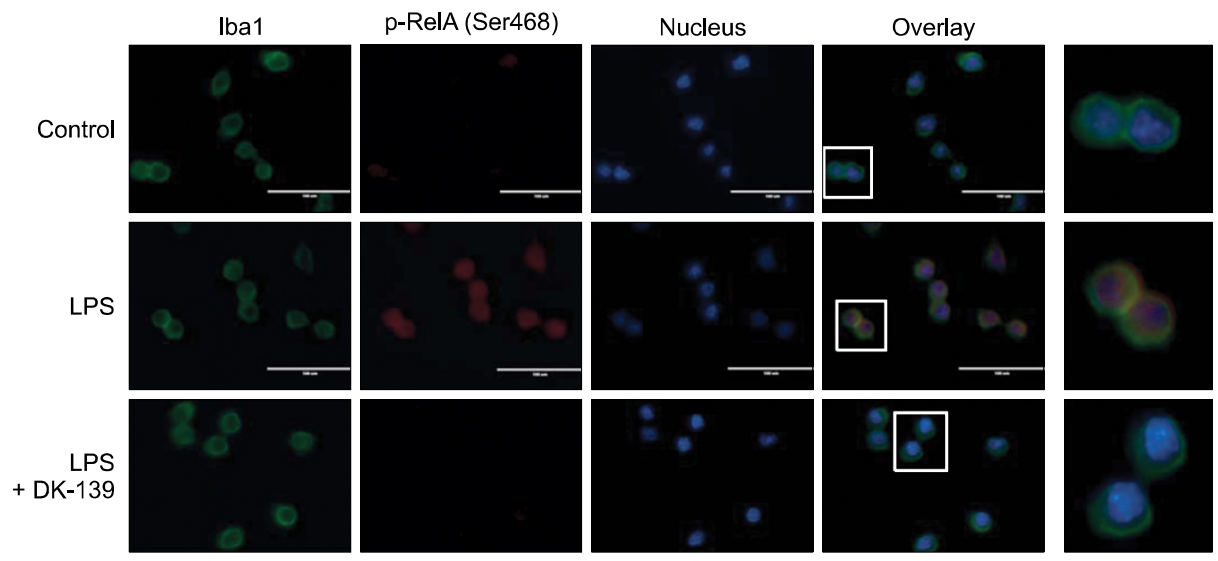

Figure 3. Inhibitory effect of DK-139 on LPS-induced NF-KB activation. (A) BV2 microglial cells were treated with different concentrations of DK-139 for $30 \mathrm{~min}$, followed by treatment with $0.5 \mu \mathrm{g} / \mathrm{ml}$ LPS for $10 \mathrm{~min}$. Whole-cell lysates were prepared, and Western blotting was performed using phospho-specific antibodies against $I_{\kappa} B \alpha$ (Ser32) and p65/RelA (Ser468), as indicated. GAPDH was used as an internal control to ensure equal protein loading. Each blot is representative of at least three independent experiments. (B) BV2 microglial cells were cultured on coverslips and pretreated with $20 \mu \mathrm{M}$ DK-139 for $30 \mathrm{~min}$ before stimulation with $50 \mathrm{ng} / \mathrm{ml}$ LPS. After $30 \mathrm{~min}$, the cells were fixed and incubated with an antibody against phospho-p65/RelA (Ser468) for $2 \mathrm{~h}$, followed by incubation with an Alexa Fluor 488-conjugated (green signal) or Alexa Fluor 555-conjugated (red signal) secondary antibody for 30 min. Nuclear DNA was stained with $1 \mu \mathrm{g} / \mathrm{ml}$ Hoechst 33258 for $10 \mathrm{~min}$ (blue signal). Overlay images are shown on the right. Bar, $100 \mu \mathrm{m}$. (C) BV2 microglial cells were transfected with $0.1 \mu \mathrm{g}$ of the $5 \times \mathrm{NF \kappa B}$-Luc plasmid, along with $50 \mathrm{ng}$ of the expression plasmid for Renilla luciferase (pRL-null), to normalize transfection efficiency. At $48 \mathrm{~h}$ post-transfection, the cells were either left untreated or treated with different concentrations of DK-139 for $30 \mathrm{~min}$, followed by treatment with $50 \mathrm{ng} / \mathrm{ml}$ LPS. After $8 \mathrm{~h}$, firefly luciferase activity was measured and normalized to the Renilla activity. The data shown represent the mean $\pm \mathrm{SD}$ of three independent experiments performed in triplicate. ${ }^{*} P<0.05,{ }^{* *} P<0.01$.

\section{DK-139 might target Akt.}

\section{Inhibition of Akt by DK-139 is involved in the suppression of IKB phosphorylation by DK-139}

To test whether DK-139 targets Akt, we investigated the effect of DK-139 on LPS-induced Akt activation in BV2 microglial cells. Western blot analysis showed that LPS increased the levels of phosphorylated-Akt at Ser-473, and this was reduced by pretreatment with DK-139 (Figure 6A). We next determined whether Akt contributes to LPS-induced NF- $\kappa B$ activation in BV2 microglial cells. Pretreatment with specific inhibitor of Akt1/2 (AKTi) effectively attenuated LPS-induced Akt and p65/RelA phosphorylation (Figure 6B). Furthermore, overexpression of the constitutively active p110 subunit of $\mathrm{PI} 3 \mathrm{~K}$ using recombinant adenovirus (Ad5/p110CAAX) led to concomitant increase in the levels of Akt and p65/RelA phosphorylation as well as the amounts of iNOS and COX2 (Figure 6C). These results suggest that DK-139 inhibits Akt by targeting the kinase domain of Akt, which leads to the inhibition of $\mathrm{I}_{\kappa} \mathrm{B}$ phosphorylation, resulting in the downregulation of NF-KB in LPS-stimulated microglial cells.

\section{Discussion}

The TLR family participates in innate and adaptive immune responses (Medzhitov et al., 1997; Rock et al., 1998). To date, ten different TLRs have been discovered in mammals; some are located on the 
A

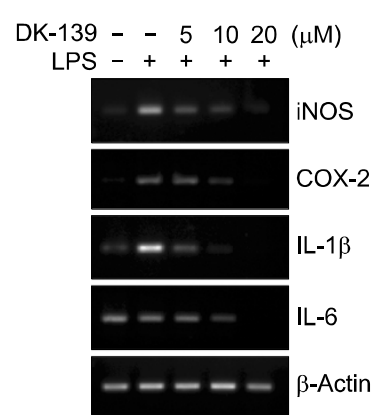

B

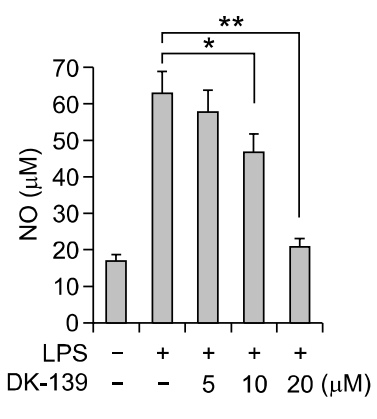

Figure 4. Inhibitory effects of DK-139 on LPS-induced production of pro-inflammatory mediators. (A) BV2 microglial cells were treated with different concentrations of DK-139 for 30 min, followed by treatment with $0.5 \mu \mathrm{g} / \mathrm{ml}$ LPS for $12 \mathrm{~h}$. Total RNA was isolated and the levels of iNOS, COX2, IL- $1 \beta$, and IL- 6 mRNA were determined by RT-PCR; $\beta$-actin mRNA was used as an internal control. (B) BV2 microglial cells were treated with different concentrations of DK-139 for $30 \mathrm{~min}$, followed by treatment with $0.5 \mu \mathrm{g} / \mathrm{ml}$ LPS for $12 \mathrm{~h}$. NO production was measured using the Griess reagent. The data represent the mean \pm SD of three independent experiments performed in triplicate. ${ }^{*} P<0.05,{ }^{* *} P<0.01$.

cell membrane (TLRs 1, 2, 4, 5, 6, and 10), while others are anchored in the endosome (TLRs 3, 7, 8, and 9) (Ospelt and Gay, 2010). Since TLRs are capable of recognizing conserved microbial structures, such as bacterial LPS and viral double-stranded RNA, they are believed to be the primary sensors of pathogenic microorganisms (Blasius and Beutler, 2010). LPS is a major component of the Gram-negative bacterial wall and a ligand for TLR4 (Chow et al., 1999). Upon LPS stimulation, TLR4 activates downstream transcription factors, such as $N F-\kappa B$, resulting in the production of a wide range of pro-inflammatory cytokines and chemokines (Ospelt and Gay, 2010). In the CNS, microglia and astroglia express TLR4 (Hanke and Kielian, 2011). However, TLR4 levels in astrocytes are much lower than in microglial cells, and astrocytes lack expression of CD14, a component of the high-affinity LPS receptor (Wright et al., 1990), suggesting that microglia are more sensitive than astrocytes to TLR4-mediated responses in the CNS (Saijo and Glass, 2011). In the present study, we show that DK-139, a new synthetic chalcone derivative, acts as an anti-inflammatory agent by blocking TLR4-mediated expression of proinflammatory genes in microglial cells.

Upon LPS stimulation, TLR4 recruits various Toll/IL-1 receptor (TIR) domain-containing adaptors, such as myeloid differentiation primary response gene 88 (MyD88), TIR domain-containing adaptor protein (TIRAP), TRIF-related adaptor molecule (TRAM), TIR domain-containing adaptor inducing IFN- $\beta$ (TRIF), and sterile alpha and HEAT-Armadillo motifs-containing protein (SARM), resulting in the
A
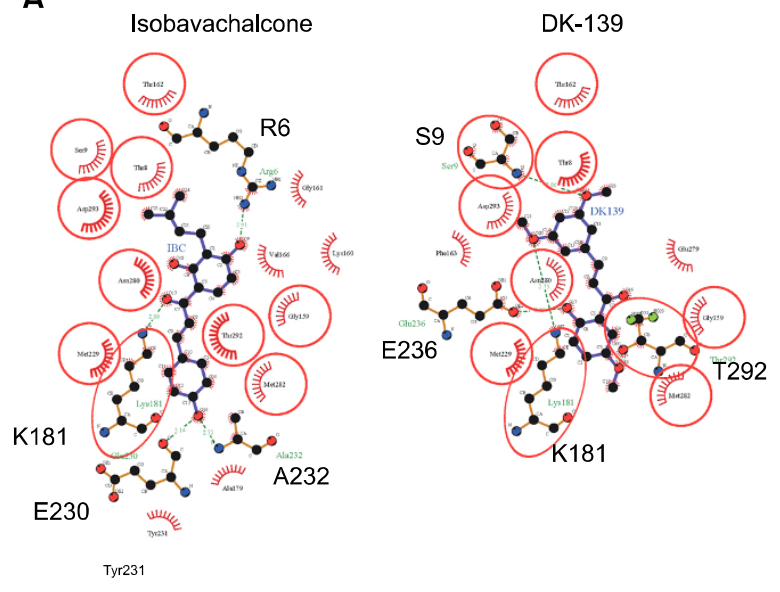

B
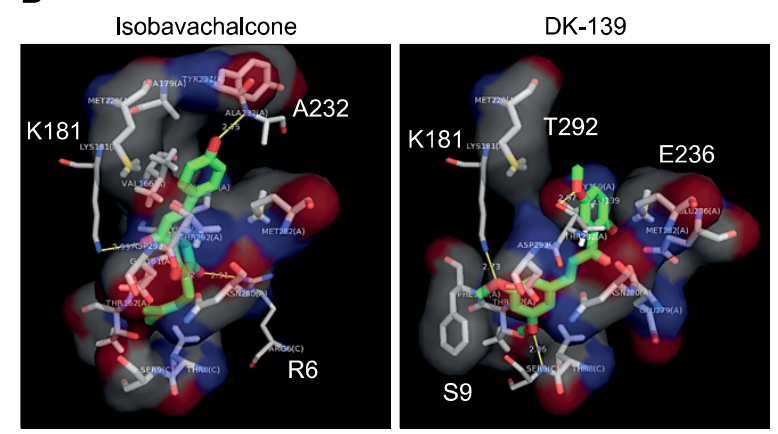

Figure 5. Molecular docking simulation of DK-139 into the ATP-binding pocket of Akt. (A) LigPlot analysis. The residues forming hydrogen bonds and hydrophobic interactions with isobavachalcone (left) and DK-139 (right). Red circles denote identical residues interacting with isobavachalcone and with DK139. (B) The 3D structural model of the binding site of isobavachalcone (left) and DK-139 (right) docked to the ATP-binding site of Akt protein, viewed in PyMOL program.

initiation of downstream signaling pathways (O'Neill and Bowie, 2007). MyD88 plays a critical role in the activation of LPS-induced NF- $\mathrm{B}$ activation through sequential activation of $\mathrm{IL}-1$ receptor-associated kinase (IRAK), TGF $\beta$-activated kinase (TAK1), and IKK (IKK $\gamma / \mathrm{Nemo}$, IKK $\alpha$, and IKK $\beta$ ). Activated IKK leads to phosphorylation at the serine residues and the subsequent degradation of $I \kappa B$, resulting in nuclear translocation and activation of $N F-\kappa B$. In the present study, we found that DK-139 reduced LPS-induced phosphorylation of $I_{\kappa} B \alpha$ at Ser-32 and of p65/RelA at Ser-468, as well as the transcriptional activity of $\mathrm{NF}-\kappa \mathrm{B}$, as revealed by a cis-acting reporter assay system in BV2 microglial cells. To confirm our results, we monitored NF-KB nuclear translocation by fluorescence microscopy. DK-139

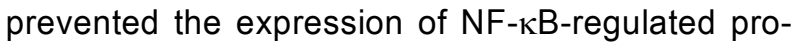
inflammatory genes, including iNOS, COX2, IL-1 $\beta$, and $I L-6$, suggesting its potential anti-inflammatory capacity through negative modulation of the $N F-\kappa B$ 
A

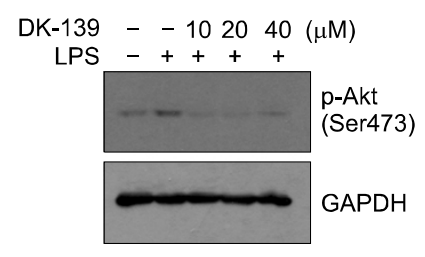

B

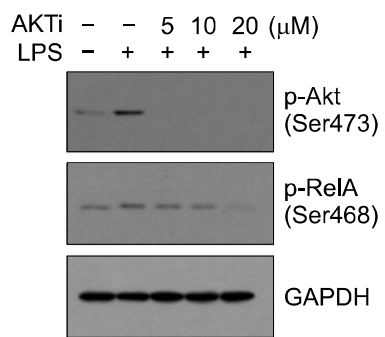

C

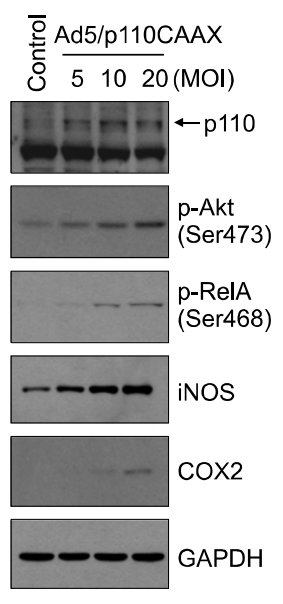

Figure 6. Inhibitory effect of DK-139 on LPS-induced Akt phosphorylation. BV2 microglial cells were treated with different concentrations of DK-139 (A), or AKTi (B) for 30 min, followed by treatment with $0.5 \mu \mathrm{g} / \mathrm{ml}$ LPS for $10 \mathrm{~min}$. Whole-cell lysates were prepared and subjected to Western blotting with phospho-specific antibodies, as indicated. GAPDH was used as an internal control to ensure equal protein loading. (C) BV2 microglial cells were infected with recombinant adenovirus expressing green fluorescence protein (Ad/GFP; Control) at $10 \mathrm{MOI}$ or dominant-active p110-CAAX (Ad5/p110CAAX) at different MOI $(5,10$, and 20) for $48 \mathrm{~h}$. Total protein extracts were prepared and subjected to Western blot analysis. GAPDH was used as an internal control to ensure equal protein loading.

signaling pathway in TLR4-activated microglia.

$\mathrm{PI} \mathrm{K}$ is a ubiquitous lipid kinase that phosphorylates $\mathrm{PI}(4,5) \mathrm{P}_{2}$ to generate $\mathrm{PI}(3,4,5) \mathrm{P}_{3}$, which results in the activation of Akt. Activated Akt phosphorylates protein substrates that function as regulators of cell proliferation and survival. It has been demonstrated that Akt enhances the nuclear translocation and transactivation potential of NF- $\mathrm{kB}$ by phosphorylating IKK $\alpha$ (Ozes et al., 1999; Madrid et al., 2000, 2001). Indeed, several studies have demonstrated the role of PI3K/Akt pathway in the activation of NF-KB (Sizemore et al., 1999; Li et al., 2003; Giri et al., 2004; Lee et al., 2006; Nam et al., 2008; Park et al., 2011). In the present study, we show that DK-139 blocks LPS-induced Akt phosphorylation, and that inhibition of Akt suppresses LPS-induced phosphorylation of p65/RelA. In addition, we found that overexpression of the $p 110$ subunit of PI3K ( $p 110 C A A X$ ) concomitantly increases the phosphorylation of Akt (Ser-473) and of p65/RelA (Ser-468). It has been demonstrated that isobavachalcone, a natural chalcone derivative (1-[2,4-Dihydroxy-3-(3-methyl-but-2-enyl)-phenyl]-3 -(4-hydroxy-phenyl)-propenone), inhibits Akt through binding to the ATP-binding site (Jing et al., 2010). We also found that DK-139 binds directly to the

ATP-binding pocket in the kinase domain of Akt, as revealed by in silico molecular docking simulations. Thus, it seems that DK-139 inhibits Akt through targeting of the ATP-binding site of Akt. There are three Akt isoforms, Akt1/PKB $\alpha, A k t 2 / P K B \beta$ and $A k t 3 / P K B \gamma$. Because Akt isoforms share greater than $80 \%$ sequence identity in the kinase domain, we cannot rule out the possibility that DK-139 is less selective to Akt isoforms. It is also possible that DK-139 targets Akt upstream kinases, such as PI3K and mTORC2 (Sarbassov et al., 2005). Further study will be aimed at identifying the molecular target of DK-139. In addition to neuroinflammation, Akt/NF-kB signaling pathway is involved in cell proliferation and survival and is frequently hyperactivated in a variety of tumor cells (Lawlor and Alessi, 2001). Our results suggest that inhibition of $A k t / N F-\kappa B$ pathway by DK-139 may provide therapeutic benefits as an adjuvant to conventional chemotherapies against diverse human tumors.

In conclusion, we have synthesized a new chalcone derivative, 2-hydroxy-3',5,5'-trimethoxychalcone (DK139), which blocks the Akt/NF-kB signaling pathway in LPS-treated BV2 microglial cells. Our data suggest that DK-139 may be useful for therapeutic manipulation of the TLR4 signaling cascade in the CNS.

\section{Methods}

\section{Cell culture and reagents}

BV2 rat microglia cells were obtained from the American Type Culture Collection (ATCC) and cultured in Dulbecco's modified Eagle's medium that was supplemented with $10 \%$ fetal bovine serum (FBS; HyClone). LPS and U0126 were purchased from Calbiochem, and Akt1/2 inhibitor (AKTi) was obtained from Sigma-Aldrich.

\section{Synthesis of DK-139}

The following process was used to generate 2-hydroxy-3', 5,5'-trimethoxychalcone (DK-139): 2-hydroxy-5-methoxy1-acetophenone (116 mg, $1 \mathrm{mmol}$ ) and 3,5-dimethoxybenzaldehyde (116 mg, $1 \mathrm{mmol}$ ) were dissolved in $15 \mathrm{ml}$ of ethanol and the temperature of the reaction mixture was adjusted to $5^{\circ} \mathrm{C}$ in an ice bath. To the cooled reaction mixture was added $50 \% \mathrm{KOH}$ solution $(1 \mathrm{ml})$, followed by stirring at room temperature for $40 \mathrm{~h}$. The reaction mixture was acidified by the addition of $6 \mathrm{~N} \mathrm{HCl}(4 \mathrm{ml})$, and extracted twice with dichloromethane. The combined organic layers were dried over $\mathrm{MgSO}_{4}$. Filtration and evaporation of the solvent gave a residue, which was purified by flash chromatography (ethyl acetate:hexane $=1: 4$ ) to afford 217 $\mathrm{mg}(69 \%)$ of 2-hydroxy-3',5,5'-trimethoxychalcone. Nuclear magnetic resonance (NMR) analyses were carried out in the Bruker Avance 400 (Bruker, Karlsruhe, Germany). The full name of the product is $(E)$-3-(3,5-dimethoxyphenyl)1-(2-hydroxy-5-methoxyphenyl)prop-2-en-1-one. The com- 
pound has the following features: melting point, $80-82^{\circ} \mathrm{C}$; ${ }^{1} \mathrm{H}-\mathrm{NMR}(400 \mathrm{MHz}) \delta$ : 3.81(s), 3.81(s), 6.62(t,2.2), 6.96(d, 9.0), 7.09(d, 2.2), 7.22(dd, 9.0, 3.1), 7.66(d, 3.1), 7.75(d, 15.5), 7.98(15.5), $11.97(\mathrm{bs})$; and ${ }^{13} \mathrm{C}-\mathrm{NMR}(100 \mathrm{MHz}) \delta$ : $55.4,55.9,103.0,107.1113 .9,118.6,120.8,122.6,123.6$, $136.4,144.9,151.7,155.9,160.7,193.3$.

\section{Cell based TLR4 activity assay}

Toll-like receptor 4 (TLR4) activity was measured using a cell-based assay, according to the manufacturer's instructions (Invitrogen). Briefly, HEK-Blue ${ }^{T M}-$ hTLR4 cells, which express hTLR4 and MD-2/CD14 coreceptor genes and a secreted embryonic alkaline phosphatase (SEAP) reporter gene, were cultured to a density of $3 \times 10^{4}$ cells in 96-well plates, and then treated with LPS in the absence or presence of DK-139. After $12 \mathrm{~h}$, the SEAP level was determined using a spectrophotometer (Molecular Devices, Emax) at $650 \mathrm{~nm}$.

\section{Western blot analysis}

BV2 microglial cells were collected and lysed in RIPA buffer, and protein samples $(20 \mu \mathrm{g})$ were then separated on a $10 \%$ SDS-polyacrylamide gel and transferred to nitrocellulose filters. The filters were blocked with $5 \%$ nonfat dry milk and probed with antibodies against phospho-Akt (Ser473), IкB (Ser32), and p65/RelA (Ser468) (Cell Signaling Technology). An antibody against glyceraldehyde-3-phosphate dehydrogenase (GAPDH; Santa Cruz Biotechnology) was used as an internal control. Positive reactions were visualized using an enhanced chemiluminescence detection system (Amersham Pharmacia Biotech).

\section{RT-PCR}

Total RNA was extracted using the Trizol RNA extraction kit (Invitrogen, Carlsbad, CA). For RT-PCR analysis, gene-specific primers for $I L-1 \beta \quad(+141 /+319$; forward, 5'-GTTGACGGACCCCAAAAGAT-3'; reverse, 5'-AAGGTC CACGGGAAAGACAC-3'), COX2 (+1323/+1692; forward, 5'-TTGTTGAGTCATTCACCAGACAGAT-3'; reverse, 5'-CA GTATTGAGGAGAACAGATGGGATT-3'), iNOS (+606/+1412; forward, 5'-CAACCAGTATTATGGCTCCT-3'; reverse, 5'-G TGACAGCCCGGTCTTTCCA-3'), IL-6 (+66/+468; forward, 5'-TTGCCTTCTTGGGACTGATGCT-3'; reverse, 5'-GTATC TCTCTGAAGGACTCTGG-3'), and $\beta$-actin $(+885 /+1233$; forward, 5'-TGGAATCCTGTGGCATCCATGAAAC-3'; reverse, 5'-TAAAACGCAGCTCAGTAACAGTCCG-3') were used. The PCR conditions for all the primers were as follows: hold for $5 \mathrm{~min}$ at $94^{\circ} \mathrm{C}$, followed by 30 cycles of denaturation at $94^{\circ} \mathrm{C}(30 \mathrm{~s})$, annealing at $55^{\circ} \mathrm{C}(30 \mathrm{~s})$, and elongation at $72^{\circ} \mathrm{C}(1 \mathrm{~min})$. The PCR products were subjected to electrophoresis on a $1 \%$ agarose gel.

\section{NO assay}

NO production was determined by measuring the released nitrite, a stable oxidative end-product of $\mathrm{NO}$, in the culture medium using the Griess Reagent System (Promega), ac- cording to the manufacturer's instructions. Briefly, $50 \mu \mathrm{l}$ of the culture supernatant of BV2 microglial cells $\left(4 \times 10^{5}\right.$ cells/well) were mixed with $50 \mu$ l of Griess reagent $(1 \%$ sulfanilamide, $0.1 \%$ naphthylethylene diamine dihydrochloride, $2 \%$ phosphoric acid) in a 96-well plate. Absorbance was measured at $540 \mathrm{~nm}$ using a microplate reader (Molecular Devices). Sodium nitrite $\left(\mathrm{NaNO}_{2}\right)$ was used as a standard.

\section{Immunofluorescence microscopic analysis}

BV2 microglial cells seeded on coverslips were pretreated with $20 \mu \mathrm{M}$ DK-139 for 30 min before stimulation with 0.5 $\mu \mathrm{g} / \mathrm{ml}$ LPS for $10 \mathrm{~min}$. The cells were then fixed and permeabilized as described previously (Shin et al., 2011b). Antibodies against lba1 (microglial marker) or phospho-p65/RelA (Ser468) were added for $2 \mathrm{~h}$, and then an Alexa Fluor 488-conjugated (Invitrogen; green signal for Ibai) or Alexa Fluor 555-conjugated (Invitrogen; red signal for phospho-RelA) secondary antibody, respectively, was added for $30 \mathrm{~min}$. Nuclear DNA (blue signal) was stained with $1 \mu \mathrm{g} / \mathrm{ml}$ Hoechst 33258 (Sigma-Aldrich). Labeled cells were examined under an EVOSf1 fluorescence microscope (Advanced Microscopy Group, Bothell, WA).

\section{Molecular docking simulation}

Molecular docking experiments were performed on an Intel Core 2 Quad Q6600 (2.4 GHz) Linux PC with Sybyl 7.3 (Tripos, St. Louis, MO). The three dimensional (3D) structure of Akt1 was obtained from the Protein Data Bank (PDB entry code: 106K; http://www.pdb.org). An apo-protein was prepared by deleting adenosine $5^{\prime}$-( $\beta, \gamma$-imido)triphosphate contained as a ligand in $106 \mathrm{~K}$. The ATP binding pocket for in silico docking was set to $5 \AA$ and the residues within $5 \AA$ were selected. Instead of adenosine $5^{\prime}$-( $\beta, \gamma$-imido)triphosphate, isobavachalcone was used as the ligand to confirm whether our docking system matched a previous report (Jing et al., 2010). The docking process was iterated 30 times and 30 docking poses were obtained. The residues forming hyfrogen bonds and hydrophobic interactions with isobavachalcone and DK-139 were viewed using LigPlot analysis (Wallace et al., 1995). The 3D structural model of the binding site of isobavachalcone and DK-139 docked to the ATP-binding site of Akt protein was viewed in PyMOL program (The PyMOL Molecular Graphics System, Version 1.3).

\section{Infection with recombinant adenovirus}

The preparation of a recombinant adenovirus that expresses the green fluorescence protein for negative control (Ad/GFP) and the dominant-active form of phosphatidylinositol 3-kinase (PI3K), Ad5/p110CAAX, has been described elsewhere (Egawa et al., 1999). Mid-log-phase cultured BV2 microglial cells were infected for $1 \mathrm{~h}$ with recombinant virus $A d / G F P$ at 10 multiplicities of infection (MOI) or Ad5/p110CAAX at different MOI (5, 10 and 20). After removal of the virus, the cells were cultured in complete medium for $48 \mathrm{~h}$, and then collected for Western blot analysis. 


\section{Statistical analysis}

All data are expressed as the mean \pm standard deviation (SD) of at least three independent experiments. Statistical analysis was performed using Student's $t$-test for two-tailed unpaired comparisons with the Microsoft Excel 2007 software. A $P$-value of $<0.05$ was considered statistically significant.

\section{Supplemental data}

Supplemental data include five figures and can be found with this article online at http://e-emm.or.kr/article/article files/SP-44-6-02.pdf.

\section{Acknowledgements}

This study was supported by a grant of the Korea Health Technology R\&D Project, Ministry of Health \& Welfare, Republic of Korea (Grant Number A101915).

\section{References}

Barnes PJ, Karin M. Nuclear factor-kappaB: a pivotal transcription factor in chronic inflammatory diseases. N Engl J Med 1997;336:1066-71

Blasius AL, Beutler B. Intracellular toll-like receptors. Immunity 2010;32:305-15

Chow JC, Young DW, Golenbock DT, Christ WJ, Gusovsky F. Toll-like receptor-4 mediates lipopolysaccharide- induced signal transduction. J Biol Chem 1999;274:10689-92

Czeh M, Gressens P, Kaindl AM. The yin and yang of microglia. Dev Neurosci 2011;33:199-209

Egawa K, Sharma PM, Nakashima N, Huang Y, Huver E, Boss GR, Olefsky JM. Membrane-targeted phosphatidylinositol 3-kinase mimics insulin actions and induces a state of cellular insulin resistance. J Biol Chem 1999;274:14306-14

Giri S, Rattan R, Singh AK, Singh I. The 15-deoxy-delta12, 14-prostaglandin $\mathrm{J} 2$ inhibits the inflammatory response in primary rat astrocytes via down-regulating multiple steps in phosphatidylinositol 3-kinase-Akt-NF-kappaB-p300 pathway independent of peroxisome proliferator-activated receptor gamma. J Immunol 2004;173:5196-208

Graeber MB, Streit WJ. Microglia: biology and pathology. Acta Neuropathol 2010;119:89-105

Hanke ML, Kielian T. Toll-like receptors in health and disease in the brain: mechanisms and therapeutic potential. Clin Sci (Lond) 2011;121:367-87

Jeong HK, Jou I, Joe EH. Systemic LPS administration induces brain inflammation but not dopaminergic neuronal death in the substantia nigra. Exp Mol Med 2010;42:823-32

Jing H, Zhou X, Dong X, Cao J, Zhu H, Lou J, Hu Y, He Q, Yang B. Abrogation of Akt signaling by Isobavachalcone contributes to its anti-proliferative effects towards human cancer cells. Cancer Lett 2010;294:167-77

Lawlor MA, Alessi DR. PKB/Akt: a key mediator of cell proliferation, survival and insulin responses? J Cell Sci 2001;114:2903-10

Lee JY, Jhun BS, Oh YT, Lee JH, Choe W, Baik HH, Ha J, Yoon KS, Kim SS, Kang I. Activation of adenosine A3 receptor suppresses lipopolysaccharide-induced TNF-alpha production through inhibition of PI 3-kinase/Akt and NF-kappaB activation in murine BV2 microglial cells. Neurosci Lett 2006;396:1-6

Li X, Tupper JC, Bannerman DD, Winn RK, Rhodes CJ, Harlan JM. Phosphoinositide 3 kinase mediates Toll-like receptor 4-induced activation of NF-kappa B in endothelial cells. Infect Immun 2003;71:4414-20

Madrid LV, Wang CY, Guttridge DC, Schottelius AJ, Baldwin AS Jr, Mayo MW. Akt suppresses apoptosis by stimulating the transactivation potential of the RelA/p65 subunit of NF-kappaB. Mol Cell Biol 2000;20:1626-38

Madrid LV, Mayo MW, Reuther JY, Baldwin AS Jr. Akt stimulates the transactivation potential of the RelA/p65 Subunit of NF-kappa B through utilization of the Ikappa B kinase and activation of the mitogen-activated protein kinase p38. J Biol Chem 2001;276:18934-40

Medzhitov R, Preston-Hurlburt P, Janeway CA Jr. A human homologue of the Drosophila Toll protein signals activation of adaptive immunity. Nature 1997;388:394-7

Nam KN, Son MS, Park JH, Lee EH. Shikonins attenuate microglial inflammatory responses by inhibition of ERK, Akt, and NF-kappaB: neuroprotective implications. Neuropharmacology 2008;55:819-25

Nimmo AJ, Vink R. Recent patents in CNS drug discovery: the management of inflammation in the central nervous system. Recent Pat CNS Drug Discov 2009;4:86-95

O'Neill LA, Bowie AG. The family of five: TIR-domaincontaining adaptors in Toll-like receptor signalling. Nat Rev Immunol 2007;7:353-64

Orlikova B, Tasdemir D, Golais F, Dicato M, Diederich M. Dietary chalcones with chemopreventive and chemotherapeutic potential. Genes Nutr 2011;6:125-47

Ospelt C, Gay S. TLRs and chronic inflammation. Int $\mathrm{J}$ Biochem Cell Biol 2010;42:495-505

Ozes ON, Mayo LD, Gustin JA, Pfeffer SR, Pfeffer LM, Donner DB. NF-kappaB activation by tumour necrosis factor requires the Akt serine-threonine kinase. Nature $1999 ; 401: 82-5$

Park HY, Han MH, Park C, Jin CY, Kim GY, Choi IW, Kim ND, Nam TJ, Kwon TK, Choi YH. Anti-inflammatory effects of fucoidan through inhibition of NF-kappaB, MAPK and Akt activation in lipopolysaccharide-induced BV2 microglia cells. Food Chem Toxicol 2011;49:1745-52

Pietta PG. Flavonoids as antioxidants. J Nat Prod 2000;63: 1035-42

Rock FL, Hardiman G, Timans JC, Kastelein RA, Bazan JF. A family of human receptors structurally related to Drosophila Toll. Proc Natl Acad Sci USA 1998;95:588-93

Saijo K, Glass CK. Microglial cell origin and phenotypes in health and disease. Nat Rev Immunol 2011;11:775-87 
Sarbassov DD, Guertin DA, Ali SM, Sabatini DM. Phosphorylation and regulation of Akt/PKB by the rictormTOR complex. Science 2005;307:1098-101

Shin SY, Hyun J, Lim Y, Lee YH. 3'-Chloro-5, 7-dimethoxyisoflavone inhibits TNFalpha-induced CXCL10 gene transcription by suppressing the NF-kappaB pathway in HCT116 human colon cancer cells. Int Immunopharmacol 2011a;11:2104-11

Shin SY, Woo Y, Hyun J, Yong Y, Koh D, Lee YH, Lim Y. Relationship between the structures of flavonoids and their NF-kappaB-dependent transcriptional activities. Bioorg Med Chem Lett 2011b;21:6036-41

Sizemore N, Leung S, Stark GR. Activation of phosphatidylinositol 3-kinase in response to interleukin-1 leads to phosphorylation and activation of the NF-kappaB
p65/RelA subunit. Mol Cell Biol 1999;19:4798-805

Wallace AC, Laskowski RA, Thornton JM. LIGPLOT: a program to generate schematic diagrams of protein-ligand interactions. Protein Eng 1995;8:127-34

Wright SD, Ramos RA, Tobias PS, Ulevitch RJ, Mathison JC. CD14, a receptor for complexes of lipopolysaccharide (LPS) and LPS binding protein. Science 1990;249:1431-3

Yadav VR, Prasad S, Sung B, Aggarwal BB. The role of chalcones in suppression of NF-kappaB-mediated inflammation and cancer. Int Immunopharmacol 2011;11: 295-309

Yao LH, Jiang YM, Shi J, Tomas-Barberan FA, Datta N, Singanusong R, Chen SS. Flavonoids in food and their health benefits. Plant Foods Hum Nutr 2004;59:113-22 